\title{
Goal-driven attentional capture by invisible colors: Evidence from event-related potentials
}

\author{
ULRICH ANSORGE \\ University of Vienna, Vienna, Austria \\ University of Osnabrück, Osnabrück, Germany \\ and Birkbeck College, University of London, London, England \\ AND \\ Monika Kiss And Martin Eimer \\ Birkbeck College, University of London, London, England
}

\begin{abstract}
We combined event-related brain potentials (ERPs) and behavioral measures to test whether subliminal visual stimuli can capture attention in a goal-dependent manner. Participants searched for visual targets defined by a specific color. Search displays served as metacontrast masks for preceding cue displays that contained one cue in the target color. Although this target-color cue was spatially uninformative, it produced behavioral spatial cuing effects and triggered an ERP correlate of attentional selection (i.e., the N2pc component). These results demonstrate that target-color cues captured attention, in spite of the fact that cue localization performance assessed in separate blocks was at chance level. We conclude that task-set contingent attentional capture is not restricted to supraliminal stimuli, but is also elicited by visual events that are not consciously perceived.
\end{abstract}

The role of selective attention for the adaptive control of cognitive processes is still under debate. Attentional selectivity is often regarded as a consequence of limited central processing capacities (cf. Wickens, 1984) but has also been described as serving the goal-directed control of perception and action (cf. Allport, 1987). The impact of goals and top-down task sets on selective attention is undisputed for stimuli that can be perceived consciously. For example, Folk, Remington, and Johnston (1992) have demonstrated that salient visual events, such as feature singletons, capture attention only when their features match a currently active task set, but not when they are task irrelevant. It is less clear how task goals affect attention when stimuli are below the threshold of awareness. Subliminal stimulus processing is often regarded as inaccessible to strategic top-down modulation (cf. McCormick, 1997). However, recent studies have shown that goals can influence the attentional selection of subliminal stimuli. Ivanoff and Klein (2003) found that subliminal peripheral cues attracted attention (as indicated by faster responses to targets at cued versus uncued locations; see also McCormick, 1997) only when they were task-relevant, suggesting that task sets modulate attentional processes triggered by subliminal stimuli (see also Scharlau \& Ansorge, 2003, for similar task-dependent effects of subliminal cues on temporal order judgments).

Our aim was to obtain electrophysiological and behavioral evidence for the attentional selection of subliminal stimuli that is determined by current task sets. We used a spatial cuing task in which target search arrays were preceded by spatially uninformative cues with colors that either matched or did not match the current task set. Previous studies (e.g., Folk et al., 1992) found spatial cuing effects indicative of attentional capture (i.e., faster responses to visual search targets presented at cued as compared with uncued locations) only when cues possessed target-defining colors. In these experiments, cues were not masked and thus were accessible to awareness. Here we used a similar logic to test whether target-color cues capture attention when they are masked and thus not consciously perceived.

On each trial, a cue display with four small rings in four different colors preceded a subsequent display with four larger angular figures. Because the inner contours of the larger figures surrounded the outer contours of the preceding smaller rings (see Figure 1), the cue display was made invisible by metacontrast masking (cf. Breitmeyer \& Ogmen, 2006). We used two tasks. In the search task, participants searched for a color target among the visible angular stimuli. Target color varied across participants. On half of the trials, the target was shown with three differently colored distractors, and participants indicated whether the color target was a square or a diamond. On the other half of the trials, four differently colored distractors were shown without a color target. The preceding cue display contained one ring in the target color together with three rings in three different nontarget colors. The positions of the color cue and the subsequent color target

U. Ansorge, ulrich.ansorge@univie.ac.at 


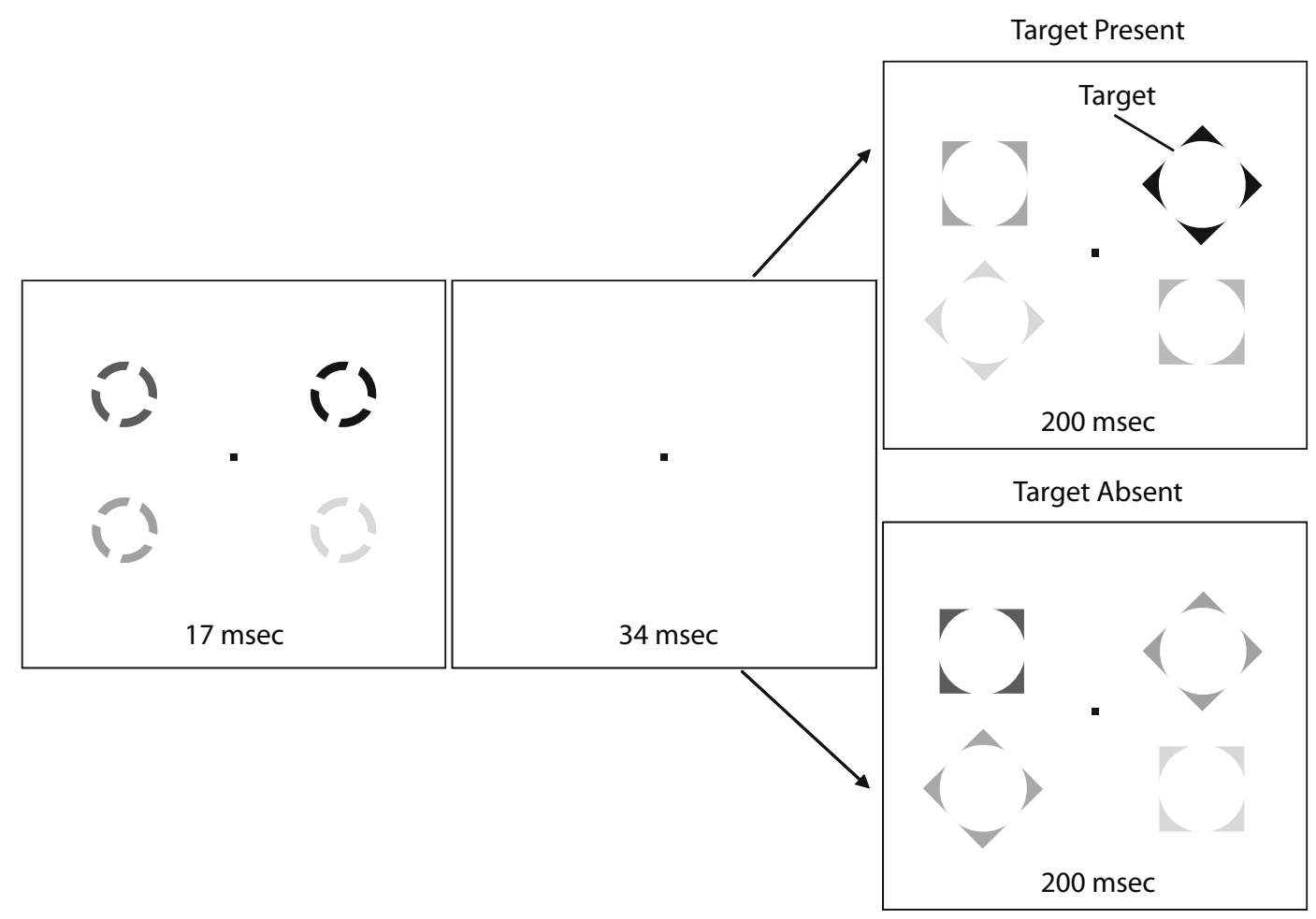

Figure 1. Example of a cue display (left side), a target-present display (top right), and a target-absent display (bottom right). Stimuli are not drawn to scale. Different colors are represented as different shades of gray.

were uncorrelated. This search task was followed by a cue localization task with an identical stimulus setup but with different task instructions. Participants now ignored the angular figures, and on each trial reported on which side the target-color cue had been presented among the rings.

If search for a specific target color determines attentional capture by subliminal stimuli, masked target-color cues should capture attention in the search task. Responses to color targets should be faster on valid trials, in which each target and its preceding target-color cue appear at the same location, than on invalid trials, in which they appear at different locations. To obtain electrophysiological evidence for attentional capture by subliminal cues, we measured event-related brain potentials (ERPs) evoked by the target-color cue. We focused on the N2pc component, an enhanced negativity over posterior scalp electrodes contralateral to the side of an attended visual stimulus elicited between 180 and $300 \mathrm{msec}$ poststimulus. This N2pc reflects the attentional selection of relevant among irrelevant visual stimuli (e.g., Eimer, 1996; Luck \& Hillyard, 1994; Woodman \& Luck, 2003). In a previous experiment, Eimer and Kiss (2008) demonstrated an $\mathrm{N} 2 \mathrm{pc}$ reflecting task-set contingent attentional capture by supraliminal cues. Attentional capture by subliminal target-color cues should therefore also be reflected by an N2pc.

If metacontrast masking renders the cue invisible, cue localization performance should be at chance level. We also measured the N2pc in response to target-color cues in the cue localization task to determine whether these cues attract attention even when they are not reported accurately (see Woodman \& Luck, 2003, for dissociations between awareness and attention).

\section{METHOD}

\section{Participants}

Eight paid volunteers ( 5 female, mean age 25 years) participated. Each reported normal or corrected-to-normal vision.

\section{Stimuli and Procedure}

Two successive displays were shown on each trial (Figure 1). The first consisted of four equidistant rings (each subtending $1.3^{\circ}$ ) in different colors, presented for $17 \mathrm{msec}$ on the corners of an imaginary square (eccentricity of $4.3^{\circ}$ ). The second display contained four larger $\left(1.6^{\circ}\right)$ angular figures in different colors, presented for $200 \mathrm{msec}$ at the same locations as the preceding circular figures. Two of these were diamonds, and two were squares. The stimulus onset asynchrony (SOA) between the two displays was $51 \mathrm{msec}$. A central fixation point was present throughout each trial.

In the target search task, participants searched for a predefined visible angular color target. They were instructed to press the left response key if the color target was a diamond and the right response key if it was a square, or vice versa (balanced across participants). Randomized across participants, target color (with CIE chromaticity $x$ - and $y$-coordinates in brackets) was red (.619/.333), green (.295/.579), brown (.439/.470), or purple (.276/.138). A color target was present on $50 \%$ of all trials and was accompanied by three distractors, which were selected randomly (without replacement) from the remaining (nontarget) colors plus gray $(.288 / .311)$. All colors were equiluminant $\left(8 \mathrm{~cd} / \mathrm{m}^{2}\right)$. The remaining target-absent trials contained four nontarget color distractors. The first display, 
which preceded the target-present or target-absent search displays, always contained one ring (cue) in the target color that was presented together with three rings in three different nontarget colors, which were selected independently of the subsequent angular distractors' colors. The positions of target-color cue and target were uncorrelated. Task instructions did not include any reference to these cues. All cue and target locations were equiprobable in a random order, as were target-present and target-absent trials. Feedback was provided after each block.

The subsequent cue localization task was identical, except for task instructions. Participants were shown the display sequence in slow motion and were instructed to report the side of the circular target-color cue with a left or right key response and to guess if in doubt. They were informed that a target-color cue would appear in each trial and that it was equally likely to appear at any position. Blocks contained 64 trials, and no feedback was given. Participants completed 12 target search blocks, followed by 4 cue localization blocks.

\section{EEG Recording and Analysis}

Horizontal electrooculograms (HEOGs) and electroencephalograms (EEGs) were DC recorded from 25 sites with $\mathrm{Ag} / \mathrm{AgCl}$ electrodes, with impedances below $5 \mathrm{k} \Omega$, low-pass filter setting of $40 \mathrm{~Hz}$, and a sampling rate of $500 \mathrm{~Hz}$. The left ear was the online reference, and EEG data were re-referenced offline to an average across ears. Saccades (voltage $> \pm 30 \mu \mathrm{V}$ in HEOG), eye blinks (voltage $> \pm 60 \mu \mathrm{V}$ at $\mathrm{FPz}$ ), and muscle artifacts (voltage $> \pm 80 \mu \mathrm{V}$ at any electrode) were excluded. ERPs were calculated for $400 \mathrm{msec}$ after cue onset relative to a $100-\mathrm{msec}$ precue baseline. N2pc amplitudes in response to targetcolor cues were quantified as mean ERP amplitudes at PO7 and PO8 in the 200- to 260-msec interval after cue onset, for each combination of task, trial type (target-color stimulus present vs. absent in the second display), and target-color cue location (left vs. right hemifield), but are collapsed across all four positions of the target or target-color mask in the second display. The N2pc triggered by color targets in the second display of the search task was also quantified and compared to the N2pc elicited by target-color cues.

\section{RESULTS}

\section{Target Search Task}

We rejected $1.9 \%$ of all trials because responses were faster than $100 \mathrm{msec}$ or slower than $1,500 \mathrm{msec}$. Correct response times (RTs) and arc-sine-transformed error rates were subjected to repeated measures ANOVAs with the variables validity (valid vs. invalid) and preceding trial (target present vs. target absent). ${ }^{1}$ Responses were faster in valid than in invalid trials (501 vs. $518 \mathrm{msec})$, resulting in a main effect of validity $[F(1,7)=84.38, p<.001]$. Overall error rate was $2 \%$ and was not affected by the variable validity $[F(1,7)=1.05, p=.34]$.

\section{Cue Localization Task}

To investigate cue visibility, we calculated individual $d^{\prime}$, a sensitive index of stimulus visibility (cf. Reingold \& Merikle, 1988), for each combination of trial type (target present vs. absent) and target-color cue location (left vs. right). Right buttonpresses counted as hits if the cue was on the right and as false alarms (FAs) if the cue was on the left, and vice versa for left responses. Hit and FA rates were $z$-transformed and were averaged across left and right responses, separately for target-present and targetabsent trials. FA rates were subtracted from hit rates to obtain $d^{\prime}$ values (cf. Green \& Swets, 1966); $d^{\prime}$ did not differ significantly from zero, indicating chance performance in the cue localization task. On target-absent trials, $d^{\prime}$ was $0.12[t(7)=1.11, p=.29]$. On target-present trials, $d^{\prime}$ was $0.14[t(7)=1.64, p=.14]$.

To directly compare cue visibility in the cue localization task against the magnitude of the cuing effect in the target search task, we calculated a $d^{\prime}$ analogue for the search task on the basis of correct RTs to search targets. Trials in which RTs were faster than the median RT were classified as hits when they were valid and as FAs when they were invalid, because cue-induced attentional capture should result in faster RTs in valid than in invalid trials. The resulting $d_{\mathrm{RT}}^{\prime}(0.33)$ differed from zero $[t(7)=7.21$, $p<.01]$ and was larger than $d^{\prime}$ in the cue-localization task $[t(7)=2.19, p<.05$, one-tailed]. There was no significant correlation between $d_{\mathrm{RT}}^{\prime}$ and $d^{\prime}[r(8)=.20, p=$ $.62]$, indicating that residual deviations from chance visibility performance were not associated with larger cuing effects.

\section{Cue N2pc}

Figure 2 shows ERPs time-locked to cue onset at lateral posterior electrodes $\mathrm{PO} 7$ and PO8 contralateral and ipsilateral to the target-color cue, separately for the search and cue localization tasks, together with topographical ERP difference maps for the N2pc time window (200$260 \mathrm{msec}$ after cue onset). Target-color cues triggered an $\mathrm{N} 2 \mathrm{pc}$ in the search task but not in the cue localization task. ERP mean amplitudes in the N2pc time window were subjected to a repeated measures ANOVA with the variables laterality (electrode contralateral vs. ipsilateral to the hemifield of the target-color cue), trial type (target present vs. target absent), and preceding trial (preceding target present vs. preceding target absent; see note 1), separately for the search and cue localization tasks.

In the search task, a significant laterality effect $[F(1,7)=7.3, p<.05]$ demonstrated that subliminal cues elicited an N2pc. There was a reliable laterality $\times$ trial type interaction $[F(1,7)=6.4, p<.05]$ due to the larger $\mathrm{N} 2 \mathrm{pc}$ amplitudes in target-absent trials than in targetpresent trials (see Figure 3). Follow-up analyses revealed the effect of laterality on target-absent trials as significant $[F(1,7)=11.8, p<.05]$ but only approaching significance on target-present trials $[F(1,7)=4.1, p=.08]$.

In contrast to the search task, no effect of laterality and no laterality $\times$ trial type interaction were present in the cue localization task (both $F s<1$ ), suggesting that no N2pc was elicited in this task. This difference between tasks was corroborated in an analysis of N2pc mean amplitudes that included the variable task instruction (search vs. cue localization). A significant interaction between laterality and task instruction $[F(1,7)=18.9, p<.01]$ supported the conclusion that different task sets determined whether subliminal cues elicited an N2pc.

\section{Target N2pc}

Figure 3 shows the N2pc obtained in the search task in response to the color-defined search target, together with an N2pc scalp distribution map. ERPs are time-locked to 
A

A Search Task

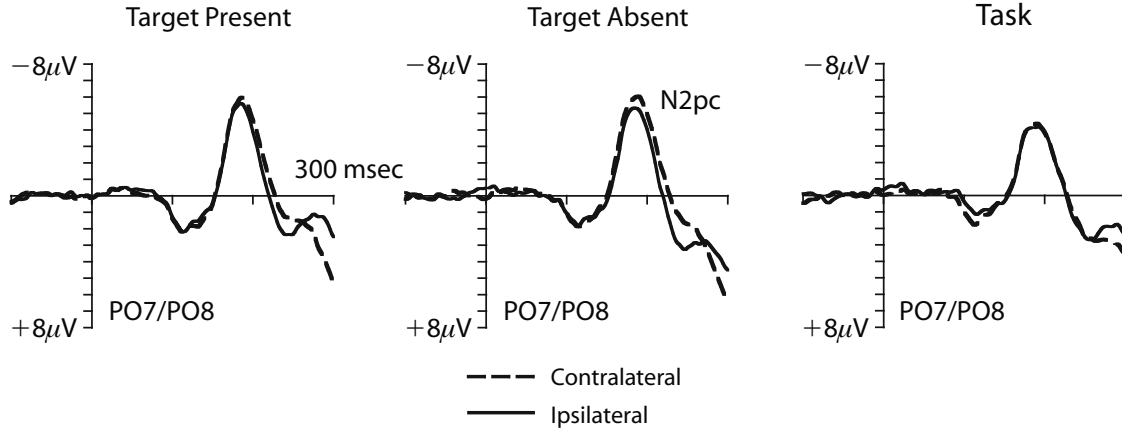

B

Scalp Potential Distributions of Contra-Ipsilateral Differences (200-260 msec)
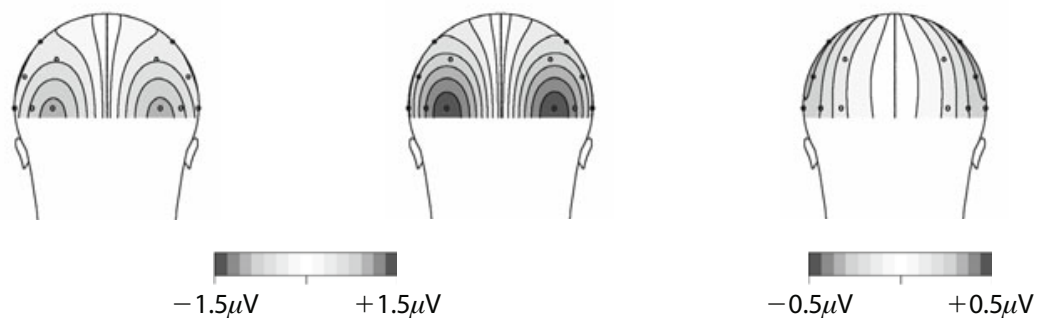

Figure 2. (A) ERPs elicited at electrode sites PO7 and PO8 contralateral (dashed lines) and ipsilateral (solid lines) to the target-color cue in the search task (shown separately for targetpresent and target-absent trials) and in the cue localization task (collapsed across targetpresent and target-absent trials). (B) Scalp distribution maps obtained during the N2pc time window (200-260 msec after cue onset). Maps represent differences between brain activity over ipsilateral and contralateral hemispheres, constructed by spherical spline interpolation (Perrin, Pernier, Bertrand, \& Echallier, 1989) after mirroring difference amplitudes to obtain symmetrical but inverse amplitude values for both hemispheres.

cue onset, but are collapsed across all target-color cue locations, and thus show the target-elicited N2pc without any $\mathrm{N} 2$ pc activity attributable to the cue. Figure 3B also shows difference waveforms computed by subtracting ipsilateral ERPs from contralateral ERPs for the target N2pc and for the cue N2pc on target-present and target-absent trials. As expected, the latency difference between the cue and target N2pcs corresponded to the 51-msec SOA between cue and target arrays. Target N2pc peak latency was $284 \mathrm{msec}$; 236 and $226 \mathrm{msec}$ for the cue N2pc on target-absent and target-present trials. A jackknife-based procedure (Ulrich \& Miller, 2001) was used to determine and compare N2pc peak latencies. Analyses confirmed the delay of the target $\mathrm{N} 2$ pc relative to cue N2pcs on target-present and targetabsent trials [both $F_{\text {corrected }} \mathrm{s}(1,7)>13.6$, both $p \mathrm{~s}<.001$ ]. A comparison of cue and target $\mathrm{N} 2 \mathrm{pc}$ mean amplitudes (computed for 60-msec time windows centered on N2pc peak latency) confirmed that the target-elicited N2pc was larger than the cue-elicited N2pc in both target-present and target-absent trials [both $t \mathrm{~s}(7)>4.70$, both $p \mathrm{~s}<.01$ ].

\section{DISCUSSION}

The present experiment demonstrates the ability of subliminal stimuli with task-relevant features to cap- ture attention. Performance in the cue localization task did not differ from chance, indicating that observers had little if any awareness of masked target-color cues. Yet these cues produced behavioral cuing effects in the search task and triggered an N2pc. In contrast to previous studies of attentional capture with supraliminal cues (cf. Folk et al., 1992), we eliminated salience-based subliminal factors: Target-color cues were accompanied by distractor rings in three different equiluminant colors, in order to ensure that any electrophysiological and behavioral attentional capture effects could not be attributed to low-level perceptual salience gradients in the cue display. Our results therefore provide evidence that the subliminal cues captured attention depending on their match to the top-down goals. The observed dissociation between cue visibility in the localization task and cuing effects in the search task further supports the conclusion that cue-induced attentional capture does not depend on perceptual awareness.

The fact that cue-induced N2pc amplitudes were somewhat smaller on target-present than on target-absent trials may be related to the additional presence of a target N2pc on the former trials. In fact, the target-induced N2pc was not only delayed by about $50 \mathrm{msec}$ relative to the cueinduced N2pc (Figure 3), as expected, but was also con- 


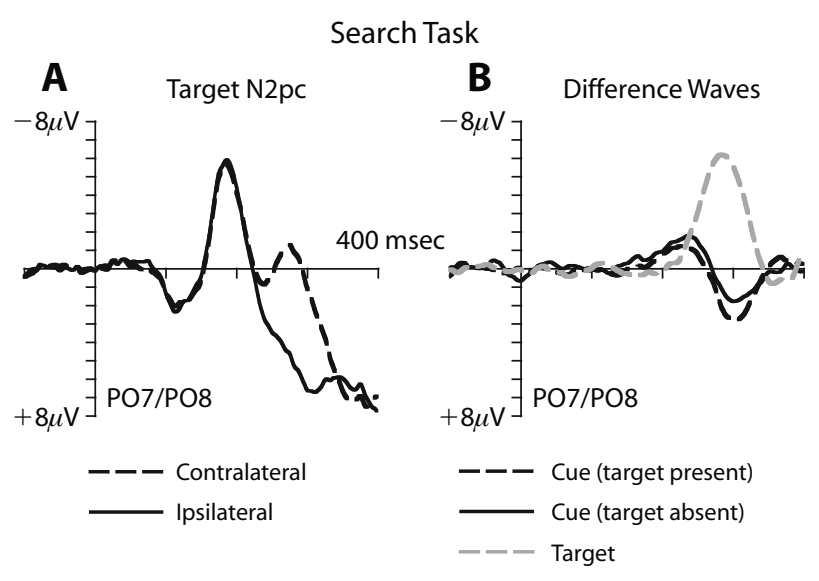

C Difference Map (250-310 msec)

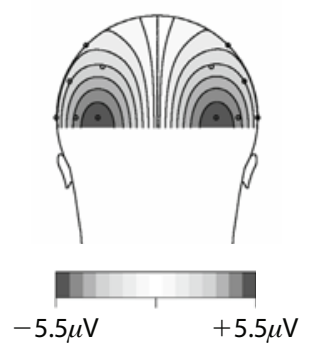

Figure 3. (A) ERPs at PO7 and PO8 contralateral (dashed line) and ipsilateral (solid line) to the side of the target in the search task, collapsed across all target-color cue locations. (B) Difference waves obtained by subtracting ipsilateral from contralateral ERPs, showing the target N2pc and the cue-induced N2pes on target-present and target-absent trials. (C) Scalp distribution map for the target $\mathbf{N 2 p c}$ (250-310 msec after cue onset).

siderably larger in amplitude. It is likely that this difference is due primarily to the fact that target arrays were not masked, but it could also reflect differences in the taskrelevance of cue and target arrays.

Whereas subliminal target-color cues triggered an $\mathrm{N} 2 \mathrm{pc}$ in the search task, indicating goal-dependent attentional capture, no N2pc was observed in the cue localization task, in spite of physically identical cue arrays in both tasks and an explicit instruction to search for the target-color cue. This dissociation suggests that attentional goal states may have differed between the tasks. In the search task, response-relevant stimuli were clearly visible, thus enabling participants to realize their search goals successfully on $50 \%$ of all trials. In the cue localization task, in which target-color stimuli were masked and localization performance was at chance level, search goals could not be applied successfully and were not reinforced. This may have led participants to change their task set (e.g., to search for flicker instead of color; see also Ansorge, Becker, \& Breitmeyer, 2009) or to abandon their goals. The absence of an N2pc in the cue localization task suggests that goal-dependent attentional capture by subliminal stimuli requires the occasional execution of a goal-directed search among supraliminal stimuli as re- inforcement for the current task set. This notion is in line with the fact that Woodman and Luck (2003) observed an $\mathrm{N} 2 \mathrm{pc}$ to undetected masked shape targets under conditions in which target shapes were clearly visible on half of all trials. Along similar lines, Ivanoff and Klein (2003) found behavioral evidence for attentional capture by taskrelevant subliminal peripheral cues when these cues were visible in $50 \%$ of all trials.

Our finding that subliminal stimuli can trigger goaldependent attentional capture may seem inconsistent with claims that subliminal processing is insensitive to task goals. This claim is often based on demonstrations that subliminal information cannot be used to adaptively change task sets. For instance, subliminal information about the probability that an expected target stimulus is either semantically related or unrelated cannot be used strategically (cf. Cheesman \& Merikle, 1985). The present study shows that once a task goal has been set up, it affects the attentional selection of subliminal stimuli. Stimulus awareness may thus be necessary for creating or changing task goals but not for the application of a goal once it has been created.

\section{AUTHOR NOTE}

The present study was supported by GRC Grants AN 393/2-1 and AN 393/5-1 (Germany) and by a BBSRC Grant (U.K.). M.E. holds a Royal Society-Wolfson Research Merit Award. The authors thank Franziska Worschech for technical assistance. Address correspondence to U. Ansorge, Faculty of Psychology, University of Vienna, Liebiggasse 5, A-1010 Vienna, Austria (e-mail: ulrich.ansorge@univie.ac.at).

\section{REFERENCES}

Allport, A. (1987). Selection for action: Some behavioral and neurophysiological considerations of attention and action. In H. Heuer \& A. F. Sanders (Eds.), Perspectives on perception and action (pp. 395419). Hillsdale, NJ: Erlbaum.

Ansorge, U., Becker, S. I., \& BreitMeyer, B. G. (2009). Revisiting the metacontrast dissociation: Comparing sensitivity across different measures and tasks. Quarterly Journal of Experimental Psychology, 62, 286-309.

Breitmeyer, B. G., \& Ogmen, H. (2006). Visual masking: Time slices through conscious and unconscious vision. Oxford: Oxford University Press.

Cheesman, J., \& Merikle, P. M. (1985). Word recognition and consciousness. In D. Besner, T. G. Waller, \& G. E. MacKinnon (Eds.), Reading research: Advances in theory and practice (pp. 311-342). San Diego: Academic Press.

EIMER, M. (1996). The N2pc component as an indicator of attentional selectivity. Electroencephalography \& Clinical Neurophysiology, 99, 225-234.

EIMER, M., \& Kiss, M. (2008). Involuntary attentional capture is determined by task set: Evidence from event-related brain potentials. Journal of Cognitive Neuroscience, 20, 1423-1433.

Folk, C. L., Remington, R. W., \& Johnston, J. C. (1992). Involuntary covert orienting is contingent on attentional control settings. Journal of Experimental Psychology: Human Perception \& Performance, 18, 1030-1044.

Green, D. M., \& Swets, J. A. (1966). Signal detection theory and psychophysics. New York: Wiley.

IvanofF, J., \& Klein, R. M. (2003). Orienting of attention without awareness is affected by measurement-induced attentional control settings. Journal of Vision, 3, 32-40.

LUCK, S. J., \& Hillyard, S. A. (1994). Spatial filtering during visual search: Evidence from human electrophysiology. Journal of Experimental Psychology: Human Perception \& Performance, 20, 1000 1014. 
Maljkovic, V., \& NaKayama, K. (1994). Priming of pop-out: I. Role of features. Memory \& Cognition, 22, 657-672.

McCormick, P. A. (1997). Orienting attention without awareness. Journal of Experimental Psychology: Human Perception \& Performance, 23, 168-180.

Perrin, F., Pernier, J., Bertrand, O., \& Echallier, J. F. (1989). Spherical splines for scalp potential and current density mapping. Electroencephalography \& Clinical Neurophysiology, 72, 184-187.

ReIngold, E. M., \& MerikLe, P. M. (1988). Using direct and indirect measures to study perception without awareness. Perception \& Psychophysics, 44, 563-575.

Scharlau, I., \& ANSORge, U. (2003). Direct parameter specification of an attention shift: Evidence from perceptual latency priming. Vision Research, 43, 1351-1363.

Ulrich, R., \& Miller, J. (2001). Using the jackknife-based scoring method for measuring LRP onset effects in factorial designs. Psychophysiology, 38, 816-827.

WickENS, C. D. (1984). Processing resources in attention. In R. Parasuraman \& D. R. Davies (Eds.), Varieties of attention (pp. 63-102). Orlando, FL: Academic Press.

Woodman, G. F., \& LucK, S. J. (2003). Dissociations among attention, perception, and awareness during object-substitution masking. Psychological Science, 14, 605-611.

\section{NOTE}

1. This variable was included in all behavioral and ERP analyses to test whether the presence of a color target in trial $n$ modulated attentional capture by target-color cues in trial $n+1$ (cf. Maljkovic \& Nakayama, 1994). No significant interactions between validity and preceding trial were found for RTs $[F(1,7)=2.80, p=.14]$ or for error rates $[F(1,7)=$ $1.23, p=.30$ ], suggesting that capture was not affected by intertrial color priming. However, responses were faster and more accurate on trials that followed target-present trials than on trials that followed target-absent trials (496 vs. $524 \mathrm{msec} ; 1.5 \%$ vs. $2.5 \%$ ), resulting in main effects of preceding trial for RTs $[F(1,7)=19.54, p<.01]$ and error rates $[F(1,7)=$ $8.00, p<.05]$. No main effects or interactions involving this variable were obtained in the ERP analyses.

(Manuscript received November 6, 2008; revision accepted for publication February 18, 2009.) 